\title{
O controle social nas ações do Conselho Municipal de Educação de Montes Claros a partir da perspectiva dos conselheiros
}

The social control in the actions of the Municipal

Council of Education of Montes Claros

from the counselors' perspective

\section{El control social en las acciones del Consejo Municipal de Educación de Montes Claros desde la perspectiva de los consejeros}

\author{
Jeovandir Campos do Prado ${ }^{[a]}$, Cecídia Barreto Almeida ${ }^{[b]}$, \\ Cláudia Rosane Parrela ${ }^{[b]^{*}}$
}

[a] Secretaria de Estado de Educação de Minas Gerais (SEE/MG), Araguari, MG, Brasil

[b] Universidade Estadual de Montes Claros (UNIMONTES/MG), Montes Claros, MG, Brasil

\section{Resumo}

O presente artigo intentou compreender, a partir das ações do Conselho Municipal de Educação de Montes Claros, formas de efetividade do controle social sob a perspectiva de atuação dos Conselheiros. Objetivou-se inferir se as práticas desenvolvidas, no âmbito 
do respectivo Conselho, contribuiram diretamente para o exercício do controle social do direito à educação para todos. Entende-se, a partir do proposto pelo Instituto Pólis (2008), que o controle social se faz importante para garantir que as políticas governamentais atendam, de fato, às necessidades prioritárias da população, concernente à melhora dos níveis de oferta e de qualidade dos serviços, assim como o controle e fiscalização dos recursos públicos. A participação ampla da sociedade no controle social fortalece as políticas públicas, tornando-as mais adequadas às necessidades da coletividade e ao interesse público com relação ao seu alcance e finalidade. Desse modo, o procedimento metodológico utilizado se apoiou em análise documental através do regimento interno e de atas, de pesquisa bibliográfica e de entrevistas com conselheiros.

Palavras-chave: Participação. Controle Social. Conselho Municipal de Educação.

\begin{abstract}
The present article tried to understand, from the actions of the Municipal Council of Education of Montes Claros, effective forms of social control under the perspective of action of the Counselors. The objective was to infer if the practices developed within the respective Council contributed directly to the exercise of social control of the right to education for all. It is understood, as proposed by the Pólis Institute (2008), that social control is important to ensure that government policies meet, in fact, the priority needs of the population, concerning the improvement of levels of supply and quality of services, as well as the control and inspection of public resources. The broad participation of society in social control strengthens public policies, making them more suited to the needs of the community and the public interest in relation to their scope and purpose. Thus, the methodological procedure used was based on documentary analysis through internal regulations and minutes, bibliographic research and interviews with counselors.
\end{abstract}

Keywords: Participation. Social Control. Municipal Council of Education. 


\section{Resumen}

El presente artículo intentó comprender, a partir de las acciones del Consejo Municipal de Educación de Montes Claros, formas de efectividad del control social bajo la perspectiva de actuación de los Consejeros. Se objetivó inferir si las prácticas desarrolladas, en el marco del respectivo Consejo, contribuyeron directamente al ejercicio del control social del derecho a la educación para todos. Se entiende, a partir de lo propuesto por el Instituto Pólis (2008), que el control social se hace importante para garantizar que las políticas gubernamentales atiendan, de hecho, a las necesidades prioritarias de la población, concerniente a la mejora de los niveles de oferta y de calidad servicios, así como el control y fiscalización de los recursos públicos. La participación amplia de la sociedad en el control social fortalece las políticas públicas, haciéndolas más adecuadas a las necesidades de la colectividad y al interés público en relación a su alcance y finalidad. De este modo, el procedimiento metodológico utilizado se apoyó en análisis documental a través del regimiento interno y de actas, de investigación bibliográfica y de entrevistas con consejeros.

Palabras clave: Participación. Control social. Consejo Municipal de Educación.

\section{O papel dos Conselhos Municipais de Educação na gestão de Políticas Educacionais}

A Constituição Federal de 1988 (CF de 1988) trouxe como uma inovação em seus preceitos: a opção da sociedade brasileira pautar-se por um regime político plural, descentralizado e democrático, que possibilitou a organização de mecanismos de participação social. Com outras palavras, o novo ordenamento constitucional apresentou uma nova configuração de Estado, mais aberto ao anseio social no domínio das políticas governamentais.

Nesse contexto, um dos pontos relevantes tratados no Brasil, a partir dos anos de 1990, nas esferas: municipal, estadual e federal, foi a implementação da gestão descentralizada e participativa, o que requereu pensar a existência de um coletivo, de um espaço em que a participação social na 
formulação e acompanhamento das políticas públicas ${ }^{1}$ pudesse ser assegurado, permitindo desse modo, adoção de princípios democratizadores também no campo educacional, especialmente, à gestão da educação pública.

Em alguns períodos que antecederam a CF de 1988, o voto era um dos poucos instrumentos de acesso à participação e influência da sociedade civil nas decisões governamentais que, em tese, possibilitava políticas que estivessem compromissadas com o interesse da maioria. $\mathrm{O}$ novo alento trazido com a promulgação da Constituição mencionada foi de legitimação, no plano das políticas públicas, de princípios e diretrizes — conforme artigos: 204, 206 e 227 — da participação popular, via organizações representativas, na formulação e condução de políticas públicas nas diferentes esferas governamentais. Para Rocha (2009), a CF de 1988 propiciou a instituição de mecanismos participativos na gestão das políticas públicas, isto é, legitimou diferentes tipos de conselhos brasileiros com base nos preceitos da gestão democrática.

Nessa perspectiva, a instituição e implementação dos Conselhos Municipais de Educação (CMEs) no Brasil, constituem-se em importante mecanismo para a atuação da defesa dos direitos educacionais afiançados pela legislação vigente. Por meio deste instrumento, é possível sensibilizar os poderes públicos municipais quanto a encargos que lhes são devidos no atendimento das demandas dos distintos segmentos, consonantes às políticas públicas da educação. Cada município possui peculiaridades, demandas e necessidades no âmbito da política educacional local, que só podem ser conhecidas pelos seus munícipes. Por este motivo, nada melhor do que

${ }^{1}$ Nesse período, têm-se a implementação e implantação dos "Conselhos Institucionalizados" ou "Conselhos Gestores", são Conselhos gerados a partir da promulgação da Constituição Federal de 1988, das Constituições Estaduais, das Leis Orgânicas Municipais e Lei de Diretrizes e Base da Educação Nacional, Lei 9.394/96. São exemplos de Conselhos Gestores na educação: Conselho Municipal de Educação, Conselho de Alimentação Escolar (CAE), Conselho de Acompanhamento e Controle Social do Fundo de Manutenção e Desenvolvimento do Ensino Fundamental e de Valorização dos Profissionais da Educação (CACS-FUNDEF), este último, alterado mais tarde para (CACS-FUNDEB) com ampliação de suas funções para toda a Educação Básica. 
a própria comunidade participar, opinar, supervisionar, fiscalizar e avaliar a política educacional pensada no município, o que pressupõe o estabelecimento de canais de comunicação entre a sociedade civil e o poder público.

Entendido desse modo, o Conselho Municipal de Educação (CME) se configura também em espaço para o exercício participativo democrático. Bordenave (1983, p. 13) salienta, "quando a população participa da fiscalização dos serviços públicos, estes tendem a melhorar em qualidade e oportunidade". Além disso, a participação social na gestão educacional contempla, por meio do exercício participativo, o fortalecimento e a consolidação de aspectos democráticos que se imbricam na sua dimensão dual, ou seja, prerrogativas e responsabilidades. É nesse sentido que Azanha insere a questão da municipalização, assunto tão debatido na década de 1990, em suas palavras:

o fundamental é municipalizar a preocupação com o problema educacional e isso não será feito por nenhuma providência legal. A municipalização precisa consistir num movimento de convocação e mobilização de todos os setores da sociedade local no sentido de salvação da escola pública (AZANHA, 1991, p. 66).

Para o autor, a sociedade civil também precisa responsabilizar-se pelos problemas da escola pública e, isso implica participação e interesse com a qualidade do ensino na sua totalidade. Nessa direção, é premente a ocupação, por parte dos distintos segmentos da sociedade, nos fóruns e conselhos legitimados pelo ordenamento constitucional de 1988. Também não devemos perder de vista que a legitimação da representação está diretamente atrelada ao comportamento participativo desses mesmos interlocutores, tangente à efetivação de suas respectivas demandas.

Em Montes Claros, assim como em tantos municípios brasileiros, conforme enfatizado pela Presidente do CME (2018), o Conselho encontrou e encontra dificuldades de funcionamento. Uma delas é a anuência de dirigentes que não se definem claramente como democráticos. Outra dificuldade apontada é a insuficiente valorização da gestão democrática. Há uma verdadeira preocupação, por parte da Presidente do CME de Montes Claros, em desenvolver a participação política de forma autônoma, 
responsável e comprometida com o interesse da população, mas a exemplo do que se detectou, ainda há segmentos sem representação, como é o caso dos segmentos da Superintendência Regional de Ensino de Montes Claros e estudantes, emancipados ou de maior idade, da rede municipal de ensino.

Para se chegar a essas observações e outras ao final desta pesquisa, optamos pelo procedimento metodológico apoiado em análise documental que incluiu: Regimento Interno e de Atas do CME de Montes Claros, de pesquisa bibliográfica diretamente ligada ao tema investigado e de entrevistas com conselheiros do referido Conselho.

\section{CME de Montes Claros: entre a paridade e o exercício de controle social}

O Município de Montes Claros está situado na Bacia do Alto Médio São Francisco, ao Norte do Estado de Minas Gerais. Possui uma população estimada para 2017, segundo o Censo do Instituto Brasileiro de Geografia e Estatística (IBGE), em 402.027 pessoas, ocupando a sexta posição no ranking do estado mineiro. O CME de Montes Claros pode ser considerado relativamente jovem. Foi criado e disciplinado pela Lei $n^{0} 3.809$, de 05 de outubro de 2007, obedecendo a princípios constitucionais preconizados na CF de 1988, da Lei de Diretrizes e Bases da Educação Nacional (LDBEN) n 9.394/96 e da proposta de reestruturação do sistema de ensino brasileiro.

O CME de Montes Claros se define, no art. $2^{\circ}$ do Regimento Interno, como órgão colegiado e permanente do Sistema Municipal de Ensino (SME), política e administrativamente autônomo, no desempenho das funções deliberativa, normativa, consultiva, mobilizadora e de controle social, sobre os temas de sua competência.

O mesmo Regimento, no seu art. $9^{\circ}$, regulamenta a composição do CME de Montes Claros da seguinte forma:

I. 05 (cinco) representantes dos órgãos governamentais do Município, indicados pelo Prefeito, sendo no mínimo 03 (três) da Secretaria Municipal de Educação, Esportes e Lazer - SMEEL; 
II. 01 (um) representante das instituições de ensino público superior, localizadas em Montes Claros em regime de alternância entre as respectivas instituições;

III. 01 (um) representante das instituições particulares de Educação Infantil localizadas em Montes Claros;

IV. 01 (um) representante das instituições filantrópicas, comunitárias e confessionais de Educação Infantil localizadas em Montes Claros;

V. 02 (dois) representantes dos estudantes, emancipados ou de maior idade, da rede pública municipal de Montes Claros;

VI. 02 (dois) representantes de pais de estudantes das escolas da rede pública municipal, sendo 01 (um) das escolas situadas na zona rural;

VII. 01 (um) representante do Conselho Municipal da Criança e do Adolescente de Montes Claros;

VIII. 02 (dois) representantes dos professores das escolas públicas municipais de Educação Básica, sendo 01 (um) das escolas rurais;

IX. 01 (um) representante dos servidores técnico-administrativos das escolas públicas municipais;

X. 01 (um) representante dos servidores técnico-pedagógicos em educação das escolas da rede pública municipal;

XI. 02 (dois) representantes dos diretores das escolas da rede pública municipal de Montes Claros;

XII. 01 (um) representante da Associação dos Deficientes de Montes Claros - ADEMOC;

XIII. 01 (um) representante dos professores/educadores das instituições filantrópicas, comunitárias e confessionais de Educação Infantil; XIV. 01 (um) representante dos professores das instituições particulares de Educação Infantil, indicado pelo Sindicato dos Professores do Estado de Minas Gerais - Regional Montes Claros - SINPRO;

XV. 01 (um) representante da Superintendência Regional de Ensino de Montes;

XVI. 01 (um) representante do Conselho Tutelar;

XVII. 01 (um) representante da Câmara Municipal de Vereadores de Montes Claros, indicado pela Mesa Diretora (MONTES CLAROS, 2007, p. 5-6).

Acrescenta-se que os membros do Conselho que representam diretores, pais de alunos, estudantes, conjunto de estabelecimentos ou entidades de âmbito municipal são indicados em processo eletivo organizado para esse fim, 
pelos seus respectivos pares. Quanto aos membros que representam professores e servidores, são indicados pelas entidades sindicais da respectiva categoria.

O CME em Montes Claros é majoritariamente ocupado pela sociedade política em detrimento da sociedade civil $^{2}$. O Conselho tem 21 membros titulares (nem todos os segmentos possuem representantes) e 24 suplentes com o mandato de 2 (dois) anos. Essa formação está representada por integrantes de várias instituições sociais. Entende-se que, como assegura Gadotti (2000, p. 169), "fixar prioridades e metas em conjunto com as representações de vários segmentos sociais permite ao executivo identificar e suprir, com maior precisão e eficácia, as necessidades existentes". Por outro lado, Matos (2007) chama a atenção para a dificuldade em garantir a participação realmente paritária dos conselheiros, igual em número e qualidade entre os representantes da sociedade política e da sociedade civil organizada.

Outro aspecto sobre a paridade observado por Gohn (2000) diz respeito não somente a questão numérica, pois tem a ver também com a quantidade de informações colocadas à disposição dos conselheiros, bem como a garantia da capacidade de atuação dos conselheiros, a partir do estabelecimento de critérios mínimos de escolha. Nessa perspectiva, O CME de Montes Claros ainda carece de uma paridade mais balanciada na sua composição, isso equilibraria o peso das decisões entre a sociedade política e a sociedade civil.

Sobre as competências dos conselheiros na vigência de seus pleitos, o Regimento Interno do CME de Montes Claros é taxativo no seu art. $8^{\circ}$ : são responsáveis por estudar e relatar, nos prazos estabelecidos, as matérias que lhes forem atribuídas pelo Presidente; submeter ao plenário todas as medidas julgadas pertinentes ao efetivo desempenho das funções do Colegiado; requerer votação de matéria em regime de urgência; protocolar

2 Neste artigo optamos por fazer a distinção entre "sociedade civil" e "sociedade política" na composição do CME de Montes Claros para evidenciar a distorção com relação à paridade, uma vez que por "sociedade civil" entende-se a sociedade interessada e envolvida no processo das políticas públicas para a educação, em contrapartida, por "sociedade política" entende-se a participação de pessoas envolvidas com a administração pública: secretários de governo, diretores de escola, funcionários enquanto representantes das escolas, etc.

Rev. Diálogo Educ., Curitiba, v. 18, n. 57, p. 369-389, abr./jun. 2018 
matéria de pauta junto à secretaria executiva; atender às convocações, comparecer e participar das reuniões para as quais forem convocados; encaminhar à Secretaria Executiva justificativa de ausência e desempenhar outras funções ou atribuições que lhes forem designadas pelo Presidente (MONTES CLAROS, 2007).

Observa-se que no rol das atribuições elencadas, somente estão descritas ações referentes ao processo interno e não totalizantes da reprentação. Em contrapartida, outras atribuições refentes à atuação pedagógica-política dos conselheiros não estão contempladas. Segundo Lima (2009a), o conselheiro tem a responsabilidade de discutir e participar de implementação de políticas públicas, na consulta, deliberação e normatização, em outras palavras, na criação de condições de comunicação com os movimentos populares e sociais, ou seja, suas atribuições vão muito além do estabelecido no documento.

Nesse sentido, adotar canais de interação com a comunidade, além de fortalecer democraticamente a educação, propicia maior participação dos envolvidos no que diz respeito à formulação das políticas públicas educacionais para o município. No entanto, o Instituto de Estudos, Formação e Assessoria em Políticas Sociais — Pólis (2008, p. 3) regista que há condições imprescindíveis para que se efetive o exercício do controle social, segundo ele:

É necessário que os representantes da sociedade tenham uma opinião bastante clara sobre a política pública a ser discutida, quais devem ser as suas prioridades, o que ela precisa ter ou fazer para garantir os direitos da comunidade e suprir suas demandas. Para isso, é importante que os movimentos, associações, fóruns e outras entidades da sociedade civil sempre busquem informações e discutam as políticas públicas, programas, ações e o orçamento de um determinado setor para depois dialogar com o Estado. Assim, ao chegar nos espaços de participação, defendem melhor uma posição discutida previamente.

O Instituto defende uma participação mais instrumentalizada da sociedade civil. Além disso, como infere Saviani (2014, p. 244), não podemos desconsiderar que a representação popular "é geralmente minoritária [...], enquanto os representantes governamentais têm a reunião desses colegiados 
como parte de sua condição de funcionário público pela qual são remunerados", preparo e conhecimento das questões educacionais mais específicas. A participação popular, no entanto, conclui Saviani, possui outra natureza em que a "democratização das instâncias responsáveis pela política educacional exige, pois, que os representantes populares participem na mesma condição dos que representam os setores governamentais" (2014, p. 244). Desse modo, uma participação mais consciente da sociedade civil ocasionará um poder maior de intervenção na política governamental no entendimento do Instituto.

O Pólis insiste na justificativa dessa participação social "mais qualificada" com maior poder de intervenção nas políticas governamentais:

Para discutir com qualidade e intervir melhor nas políticas públicas, também é fundamental que os representantes da sociedade conheçam seus direitos, os espaços de participação em que podem atuar, de que maneira é possível incidir nestes espaços, e que outras formas de pressão e monitoramento existem sobre as políticas públicas. Com o tempo, as pessoas envolvidas no controle social passam a entender melhor como funcionam as políticas, e passam a intervir com mais qualidade, apropriando-se dos termos utilizados, regras que se deve cumprir, como funciona a burocracia, os prazos que o poder público precisa cumprir, etc. O importante é ter em mente que este processo de aprendizado e formação é contínuo e permanente, e deve ser alimentado nos espaços autônomos de organização da sociedade (PÓLIS, 2008, p. 3).

Nos argumentos apresentados, a participação da sociedade tem relevância no desempenho dos conselheiros, uma vez que

A sociedade também tem o papel importante de cobrar para que sejam garantidos os mecanismos de controle social previstos em lei, bem como o acesso as informações necessárias para efetivar o controle. Deve pressionar para que se criem novos mecanismos, para que se amplie o alcance do controle social e a democratização do estado, tanto nas políticas em que já existem mecanismos de controle social como em outras áreas onde estes mecanismos não avançaram ainda. Em casos de não cumprimento do que está previsto em lei e esgotadas as possibilidades 
de diálogo, o Ministério Público pode ser acionado para cumprir papel importante na defesa de direitos e do controle social (PÓLIS, 2008, p. 3).

Vale sopesar que as ações desenvolvidas pelos conselheiros, são demasiadamente importantes, pois o exercício do controle social corresponde, de forma concisa segundo Lima (2009b, p. 34), "a uma perspectiva de participação, de ação democrática, de instrumentalização, de mobilização e práticas que influenciem no plano decisório governamental, quanto ao planejamento e financiamento dos serviços públicos”. Em consequência disso, qualquer disparidade paritária na composição dos Conselhos, como registrado no CME de Montes Claros, poderá acarretar reflexo direto na qualidade de suas ações, ou seja, o controle social terá menor efetividade diante da força e influência do poder executivo, tendo em vista a incorporação de funções cada vez mais burocratizadas dos CMEs e maior número de conselheiros com afinidade com a administração municipal.

\section{Ações do CME montes-clarense e atuação dos conselheiros}

Sobre a regularidade das reuniões do CME de Montes Claros, constata-se que no período, compreendido entre setembro de 2017 a fevereiro de 2018, o Conselho se reuniu mensalmente, excetuando o mês de janeiro, considerado de recesso das atividades escolares. Em relação aos assuntos frequentemente tratados nas reuniões, com base nas atas das reuniões ocorridas desde a retomada dos trabalhos do Conselho em setembro de 2017, momento em que a atual presidente assumiu o cargo, foram, na sua maioria, relacionados a organização e funcionamento da educação municipal. Nesse sentido, o Quadro a seguir é colaborativo. 


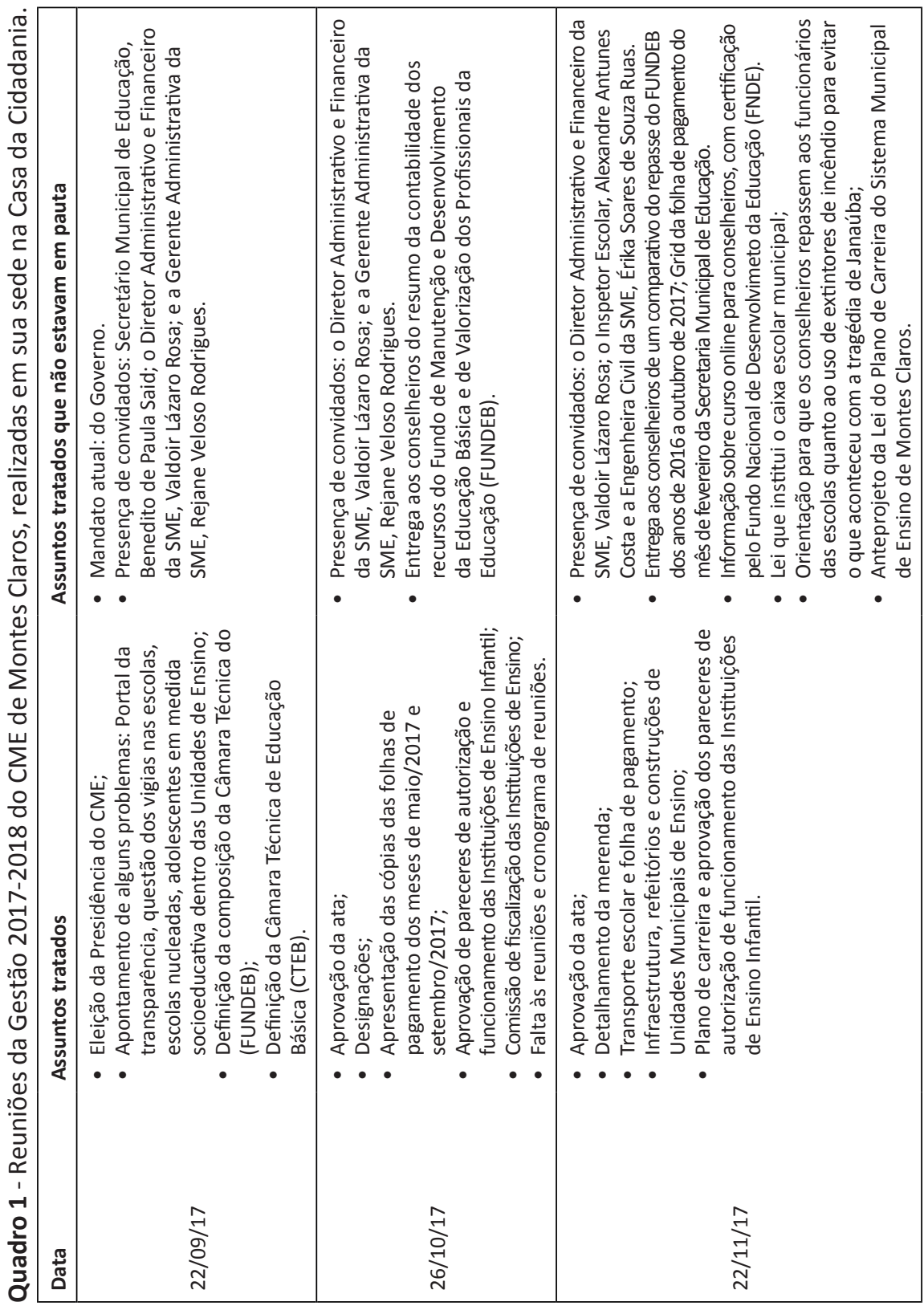




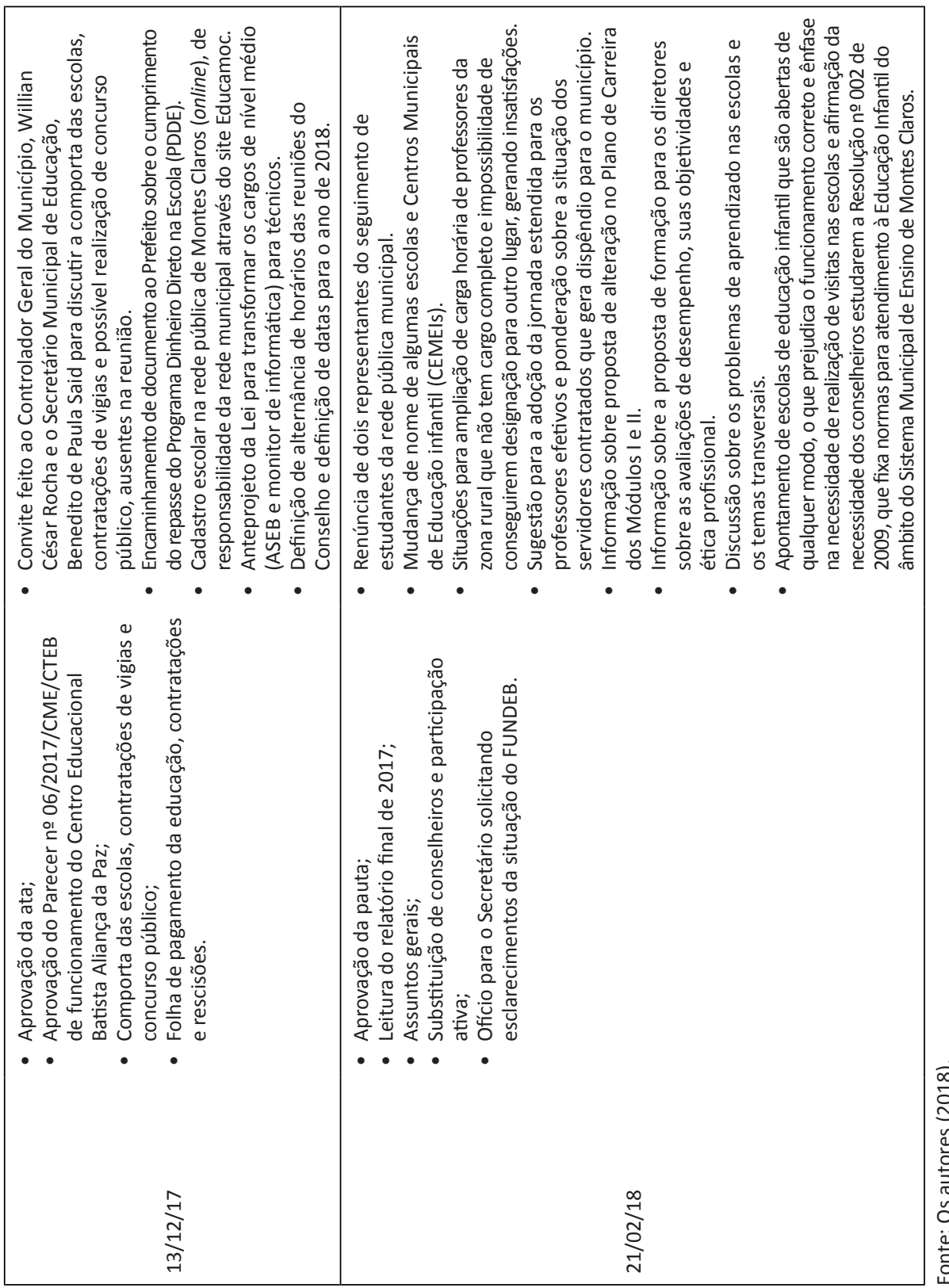


Os assuntos tratados nas atas do CME de Montes Claros ajuda-nos compreender a preocupação do Pólis (2008), referentes à participação mais instrumentalizada e a manutenção desta por meio da capacitação contínua dos conselheiros. Uma participação socialmente qualificada implica na compreensão dos mecanismos intrínsecos às políticas educacionais do município, assim como seus objetivos, direcionamentos e finalidades. Por isso, os conselheiros representantes dos diversos segmentos precisam ficar atentos para que as vontades do executivo não se sobreponham às vontades da sociedade como um todo, isto é, que na agenda governamental falte espaço para a pauta que inclua as demandas sociais.

Nesse sentido, com base em outro instrumento metodológico utilizado na presente pesquisa, nas entrevistas ${ }^{3}$ concedidas pelos conselheiros C7 e C8, os mesmos relataram que assuntos tratados nas reuniões variavam entre aprovação de recursos aplicados, aprovação de pareceres, valorização dos funcionários, questões pedagógicas, enfim, assuntos relevantes para a organização e funcionamento da educação do município. Os relatos, apenas reforçam o exposto no Quadro 1, ou seja, de que o CME de Montes Claros, como tantos outros CMEs espraiados pelo Brasil, funciona mais como suporte da administração municipal para questões objetivas relacionadas à gestão e organização da política educacional do município.

Observa-se que as reuniões do CME de Montes Claros são abertas ao público em geral. Segundo relato de uma conselheira, não é comum

${ }^{3}$ Além da análise de documentos (atas, regimentos, leis) referentes ao CME de Montes Claros, elaboramos também um roteiro de entrevistas com alguns conselheiros $(C 1, C 2, C 3, \ldots)$ contendo 8 questões: 1. Com qual regularidade ocorrem as reuniões do CME? 2. Quais assuntos são frequentemente tratados nas reuniões? 3. As reuniões do CME são abertas ao público em geral? 4. Quem está autorizado a participar das decisões e votações? 5. Como o CME dá visibilidade as decisões tomadas à população? 6. Em relação aos recursos públicos (origem, montante, destinação, aplicação) que financiam a educação básica municipal, que papel ou função desempenha o CME? 7. Como se processa a divulgação das informações e prestação de conta dos recursos destinados a educação básica? 8. Quais ações desenvolvidas pelo CME, no entendimento do conselheiro, visam garantir ou contribuir com qualidade da educação do município?

Rev. Diálogo Educ., Curitiba, v. 18, n. 57, p. 369-389, abr./jun. 2018 
a presença de pessoas da comunidade local, mesmo possuindo essa abertura. Vale lembrar que é assegurado o direito à participação popular nas formulações das políticas públicas e no controle das ações do Estado na Carta Magna e regulamentado na Lei Orgânica da Saúde (LOS), no Estatuto da Criança e do Adolescente (ECA), a Lei Orgânica da Assistência Social (LOAS) e o Estatuto das Cidades. Todas essas normativas predizem instâncias de consulta e deliberação cidadã. Ademais, fora dos canais institucionais de participação, a população em geral pode e deve acompanhar as políticas públicas no município. Entretanto, estão autorizados a participar das decisões e votações, somente os conselheiros, titulares e suplentes, indicados para a composição do Conselho.

Mas, apropriando-nos dos argumentos do Pólis (2008, p. 3) sobre alguns desafios para a concretização do controle social, será que "são produzidas informações com antecedência ou linguagem adequada sobre a realização de reuniões de conselhos, audiências públicas ou outros eventos públicos para que a população possa se organizar para participar e fazê-lo com a qualidade desejada"?

O Conselho montes-clarense, visando dar visibilidade às suas decisões à população, segundo informado pela conselheiras $C 1$, sugeriu em uma das reuniões a criação de um site para "prestar contas" das ações do CME. Podemos identificar que há realmente um problema no trânsito das informações do referido Conselho, porém numa ordem processual participativa distinta. Todavia, essa é uma característica assumida pelos "Conselhos Institucionalizados" e cada vez mais presente nos CMEs brasileiros, isto é, apropriando-nos dos argumentos de Lima (2017, p. 49), são Conselhos "gerados na esfera governamental, a partir de uma necessidade legal e cunho de repartição e verbas públicas”. De acordo com este autor, os membros deste tipo de Conselho tem seu papel político esvaziado ao assumir um caráter mais gerencial, cabendo aos mesmos a prestação de contas, quando questionado, para o executivo e à sociedade.

Nessa mesma linha, a divulgação de informações e prestação de conta dos recursos destinados a educação básica é feita através do Diário Oficial, através do diretor administrativo financeiro. Segundo informação 
do conselheiro C6, a divulgação das informações e prestação de conta dos recursos é feita por meio do Portal da Transparência da Prefeitura Municipal de Montes Claros e em Assembleia Geral ou Conselho Municipal. Desse modo, foi relatado pelo referido membro que os setores responsáveis na Prefeitura Municipal de Montes Claros, reúnem-se com os conselheiros para prestação de contas dos recursos, oportunidade em que são repassados relatórios detalhados aos conselheiros bem como para ouvir possíveis recomendações. Os fatos narrados apenas evidenciam a ideia de que os CMEs no Brasil, a exemplo do CME de Montes Claros, ocupam-se, grande parte, de funções de natureza mais técnica-administrativa.

Questionada sobre quais as ações desenvolvidas pelo CME, no entendimento do conselheiro, visam garantir ou contribuir com a qualidade da educação do município? A Presidente do CME de Montes Claros respondeu que ações como capacitação continuada para os professores dos distintos segmentos da educação; o trabalho com os conteúdos de forma não infantilizada; o desenvolvimento das competências técnica, política e humana são primordiais para garantir a qualidade da educação do município. Enfatizou que a qualidade da educação deve ser entendida como qualidade do ensino, do professor, do aluno, dos gestores, aliada à parceria com a comunidade. Afirmou também que há de se ter zelo pela educação oferecida à comunidade, uma vez que, citando Brandão (2007, p. 12), "na prática, a mesma educação que ensina pode deseducar, e pode correr o risco de fazer o contrário do que pensa que faz, ou do que inventa que pode fazer".

Com relação ao mesmo questionamento dirigido a Presidente do CME de Montes Claros, apresentamos a seguir, posições defendidas sobre o mesmo tema por outros membros do referido Conselho:

- Fiscalização e recomendações para aplicação dos recursos; Valorização dos servidores; Visitas para verificar se espaços (escolas, CEMEIs) atendem às necessidades e bem-estar das pessoas atendidas ( $C 1)$.

- Fiscalizando, orientando, cumprindo e fazendo cumprir a legislação vigente, sempre com o objetivo de proporcionar uma educação de qualidade onde todos possam ter a garantia de ser atendidos (C2). 
- Fiscalização e aplicação dos recursos da educação; Recomendação aos órgãos competentes para acompanhamento do funcionamento das escolas (administração, infraestrutura, segurança); Adequação das escolas dentro das normativas coerente com o que preconiza em leis acessibilidade, funcionários adequados, dentre outros (C3).

- Acompanhamento das ações executáveis com o recurso do FUNDEB, das ações pedagógicas, fiscalização, etc.; Atenção ao aluno, infraestrutura das escolas e Secretaria de Educação e valorização do servidor (C4). - Reuniões frequentes, possíveis soluções e sugestões; socialização de todas as ideias e solicitações necessárias; elaboração de documentos, ofícios e solicitações; acompanhamento e visitas in loco para certificação dos investimentos e outros (C5).

$\mathrm{Na}$ opinião dos conselheiros, a qualidade em educação está relacionada a aspectos objetivos e financeiros. A preocupação maior está, na visão da maioria, em fiscalizar a aplicação dos recursos da educação, conforme preconizado na legislação vigente, sem questionar se ao menos são suficientes. O senso comum entorno do termo qualidade, seus vários significados e a exploração nas agendas governamentais, o associam a padrões mensuráveis e de "racionalidade positivista", como sugere Lima (2017). Para este autor, a qualidade em educação tem a ver com aspectos objetivos e subjetivos. Criou-se uma espécie de panaceia em torno do tema que o restringiu a "uma concepção de educação ao modelo formal, regulado e regulamentado pelas políticas sociais educacionais" (LIMA, 2017, p. 59). Nessa asserção, a noção de qualidade em educação pronunciada pelos membros do CME de Montes Claros sugere estar inserida nessa lógica, ou seja, uma noção carente de elementos sociológicos e políticos importantes no campo pedagógico.

Em contrapartida, essa posição fiscalizadora assinalada na fala da maioria dos conselheiros constitui-se em uma forma legítima de controle social. É um momento específico do processo de implementação de uma política pública em que o conselheiro participa na discussão e orientação de uma política pública. 


\section{Considerações finais}

O presente artigo teve por objetivo analisar a efetividade do controle social, a partir das ações do Conselho Municipal de Educação de Montes Claros na perspectiva dos Conselheiros. Em razão disso, o caminho metodológico utilizado compreendeu, no primeiro momento, a análise de documentos, atas e Regimento Interno, no intuito de colocar em relevo ações que, porventura, contribuem para o exercício de controle social da política educacional do município. Sem perder de vista que o controle social, o compartilhar o poder de decisão entre o Estado e sociedade, constitui-se um instrumento de expressão social em que a sociedade tem a possibilidade de intervenção e interação, tangente às políticas governamentais.

Observamos que a categoria de controle social, a partir das ações do CME em Montes Claros, se restringiram às questões técnicas e burocratizadas, tais como: fiscalização, acompanhamento e aplicação dos recursos financeiros destinados à educação municipal, como ficou evidenciado no Quadro 1 sobre reuniões, pautas e assuntos tratados no CME montes-clarense. Notamos ainda, que o referido Conselho, conta com baixa participação da comunidade local nos debates promovidos pelo poder público, no tocante à política educacional do município, assim como acontece com outros CMEs.

As entrevistas, no segundo momento, outro recurso metodológico utilizado nesta pesquisa, permitiram, por meio da verbalização de seus interlocutores, identificar as limitações dos CMEs por apresentarem carcterísticas dos Conselhos legalizados após ordenamento constitucional de 1988, em que o viés participativo assume traço demasiado instrumental. Segundo Lima (2017, p. 48), os referidos Conselhos não deixam de ser canais legítimos de participação, no entanto, possuem "caráter meritocrático, [...] funções minimizadas, geralmente consultivas, adotam um caráter gerencial, ou seja, da gestão da parte que lhes cabe fiscalizar ou responder quando questionados pelo executivo, ou pela sociedade". Dito 
de outra forma, arremata Lima em seguida, "esvaziam seu papel político para atuarem como prepostos administrativos do governo local".

Nessa dimensão, o chamado controle social passa também pela necessidade de ampliação desse modelo de organização assumido pelos atuais CMEs, de funções técnico-burocratizadas, em que a participação dos seus membros resume-se à prestação de contas. Porém, pudemos observar nos registros a existência do debate e da participação crítica durante as reuniões, assim como a limitação do Conselho quanto ao resultado de alguns dos processos decisórios. Mesmo assim, destacamos que há um movimento em busca de dar voz aos conselheiros no cenário político local e de resistência às ações pautadas pelo egoísmo governamental. Os CMEs não podem abrir mão do exercício de controle social presente nas suas ações, do protagonismo e do potencial político de suas decisões, sem os quais os direitos e garantias constitucionais estarão sujeitos ao crivo interpretativo do poder estatal.

\section{Referências}

AZANHA, J. M. P. Uma idéia sobre a municipalização do ensino. Estudos Avançados, São Paulo, v. 5, n. 12, p. 61-68, 1991.

BORDENAVE, J. E. D. O que é participação. São Paulo: Brasiliense, 1983.

BRANDÃO, C. R. O que é educação. São Paulo: Brasiliense, 2007. (Coleção Primeiros Passos, 20).

GADOTTI, M. Perspectivas atuais da educação. Porto Alegre: Artes Médicas, 2000. GOHN, M. G. O Papel dos Conselhos Gestores na Gestão Urbana. In: RIBEIRO, A. C. T. (Org.). Repensando a Experiência Urbana da América Latina: questões, conceitos e valores. Buenos Aires: CLACSO, 2000. p. 175-201. 
LIMA, A. B. Conselhos Municipais de Educação no Brasil e a construção da concepção de qualidade. In: LIMA, A. B. (Org.). CMEs no Brasil: qualidade social e política da educação. Campinas: Editora Alínea, 2017. p. 47-66.

LIMA, A. B. Conselho de educação e controle social: a necessidade de movimentos sociais. In: REUNIÃO NACIONAL DA ANPED, 32., 2009, Caxambu. Anais... Caxambu: ANPED, 2009a. Disponível em: <http://www.anped.org.br/sites/default/files/gt03-5615-int.pdf>. Acesso em: 03 mar. 2018.

LIMA, A. B. Estado, educação e controle social: introduzindo o tema. In: LIMA, A. B. (Org.). Estado e controle social no Brasil. Uberlândia: Composer; Fapemig; GPEDE, 2009b. p. 17-36.

MATOS, D. F. Os conselhos municipais de políticas setoriais no contexto do federalismo brasileiro sob a perspectiva da Pesquisa de Informações Básicas Municipais. 2007. 133 f. Dissertação (Mestrado em Ciências Sociais Aplicadas) — Escola Nacional de Ciências Estatísticas, Rio de Janeiro, 2007.

MONTES CLAROS. Conselho Municipal de Educação. Lei no 3.809, de 05 de outubro de 2007. Regimento Interno. 17 dez. 2007. Disponível em: <http://www. educamoc.com.br/admin_blogs/assets/uploads/21f513025863184f997a8e13a 27af5ce.pdf >. Acesso em: 03 mar. 2018.

MONTES CLAROS. Conselho Municipal de Educação. Ata de Reunião do Conselho Municipal de Educação de Montes Claros, 22 de setembro de 2017. Montes Claros: [s.n.], 2017.

MONTES CLAROS. Conselho Municipal de Educação. Ata de Reunião do Conselho Municipal de Educação de Montes Claros, 26 de outubro de 2017. Montes Claros: [s.n.], 2017.

MONTES CLAROS. Conselho Municipal de Educação. Ata de Reunião do Conselho Municipal de Educação de Montes Claros, 22 de novembro de 2017. Montes Claros: [s.n.], 2017. 
MONTES CLAROS. Conselho Municipal de Educação. Ata de Reunião do Conselho Municipal de Educação de Montes Claros, 13 de dezembro de 2017. Montes Claros: [s.n.], 2017.

MONTES CLAROS. Conselho Municipal de Educação. Ata de Reunião do Conselho Municipal de Educação de Montes Claros, 21 de fevereiro de 2018. Montes Claros: [s.n.], 2018.

PÓLIS. Controle Social das Políticas Públicas. Repente. São Paulo: Pólis — Instituto de Estudos, Formação e Assessoria em Políticas Sociais, n. 29, agosto 2008.

ROCHA, R. Gestão descentralizada e participativa das políticas públicas no Brasil. Revista Pós Ciências Sociais, São Luís, v. 6, n. 11, p. 41-57, 2009.

SAVIANI, D. Entrevista. Revista Retratos da Escola, Brasília, v. 8, n. 15, p. 231246, jul./dez. 2014.

Recebido: 24/04/2018

Received: 04/24/2018

Recibido: 24/04/2018

Aprovado: 19/05/2018 Approved: 05/19/2018 Aprobado: 19/05/2018 